\title{
Bilateral dislocation of the shoulders due to nocturnal hypoglycaemia
}

\author{
J.C. Litchfield, ${ }^{1}$ V.Y. Subhedar, ${ }^{1}$ D.G. Beevers ${ }^{2}$ and H.T. Patel ${ }^{2}$ \\ ${ }^{1}$ Accident and Emergency Department and ${ }^{2}$ Department of Medicine, Dudley Road Hospital, Birmingham \\ B18 $7 Q H, U K$.
}

\begin{abstract}
Summary: A young insulin-dependent diabetic awoke with apparently spontaneous bilateral anterior dislocation of his shoulders. The most likely explanation was nocturnal hypoglycaemia. Similar case reports describing this complication have not been discovered.
\end{abstract}

\section{Introduction}

A significant proportion of those who present with apparently spontaneous dislocation of both shoulders have general medical conditions. These include myasthenia gravis, cerebral palsy, scapular myopathy and convulsions. ${ }^{1}$ However, we know of no reports of an association between hypoglycaemia and bilateral dislocation of the shoulders.

\section{Case report}

A 21 year old male drama student was an insulindependent diabetic and lived alone. He woke one morning feeling 'groggy' with pain and stiffness in both shoulders, was unable to give his insulin injection, and so attended hospital. He had drunk three glasses of wine during the evening.

The blood glucose concentration on arrival at $11.40 \mathrm{~h}$ was $5.4 \mathrm{mmol} / \mathrm{l}$, before he received his morning insulin (usually 60 units of Monotard). He reported that he had recently been waking at night feeling weak and hungry. In the casualty department he was noted to have generalized weakness of the upper limbs and abnormal shoulder contours, 'due possibly to deltoid wasting'. The diagnosis of bilateral anterior (subcoracoid) dislocation of the shoulders was made clinically and radiographically at about $11.00 \mathrm{~h}$ the following day, 24 hours after admission (Figure 1). Reduction was subsequently effected easily under general anaesthetic, at which time examination did not reveal abnormal joint stability. A body stocking, which was retained for 3 weeks, was used to restrict abduction and external rotation of the upper limbs, leaving the hands free. At $22.00 \mathrm{~h}$ on his second

Correspondence: J.C. Litchfield, M.B., F.R.C.S. Accepted: 10 February 1988. night in hospital, the blood glucose was $5.7 \mathrm{mmol} / \mathrm{l}$, although his glycosylated haemoglobin was $10.3 \%$ (normal range 4.9 to $8.9 \%$ ). Both shoulders exhibited a full and painless range of movement 2 months after presentation.

Subsequent electroencephalography (EEG) and isotope brain scanning were normal.

\section{Discussion}

Brown ${ }^{1}$ studied 90 cases of simultaneous bilateral dislocation of the shoulders occurring over a period of 20 years. Eighty-three of these had been previously published. He divided the patients into three separate aetiological categories. The smallest group $(23 \%)$ comprised those who had experienced violent injuries, for example simultaneous traction, or more commonly, abrupt deceleration such as a fall onto the outstretched hands. Thirty-six per cent were atraumatic. Many of these patients had neuromuscular disorders such as myasthenia gravis or cerebral palsy, or produced the dislocations voluntarily, in which cases there was laxity of the joint and/or a psychological disorder. The remainder had anatomical defects, frequently the result of previous injuries (as in group 1), and suffered habitual dislocations following trivial violence. The third and largest category $(41 \%)$, in which posterior dislocations were more common than anterior, were those caused by the acute muscular violence accompanying seizures or electrocution (including electroconvulsive therapy).

In the absence of a history of the first two categories, the search for an aetiology in our patient can be narrowed to the third group. The fact that the EEG and isotope scan were normal does not exclude the presence of a primary 'epileptic' focus in the brain. There have, however, been 

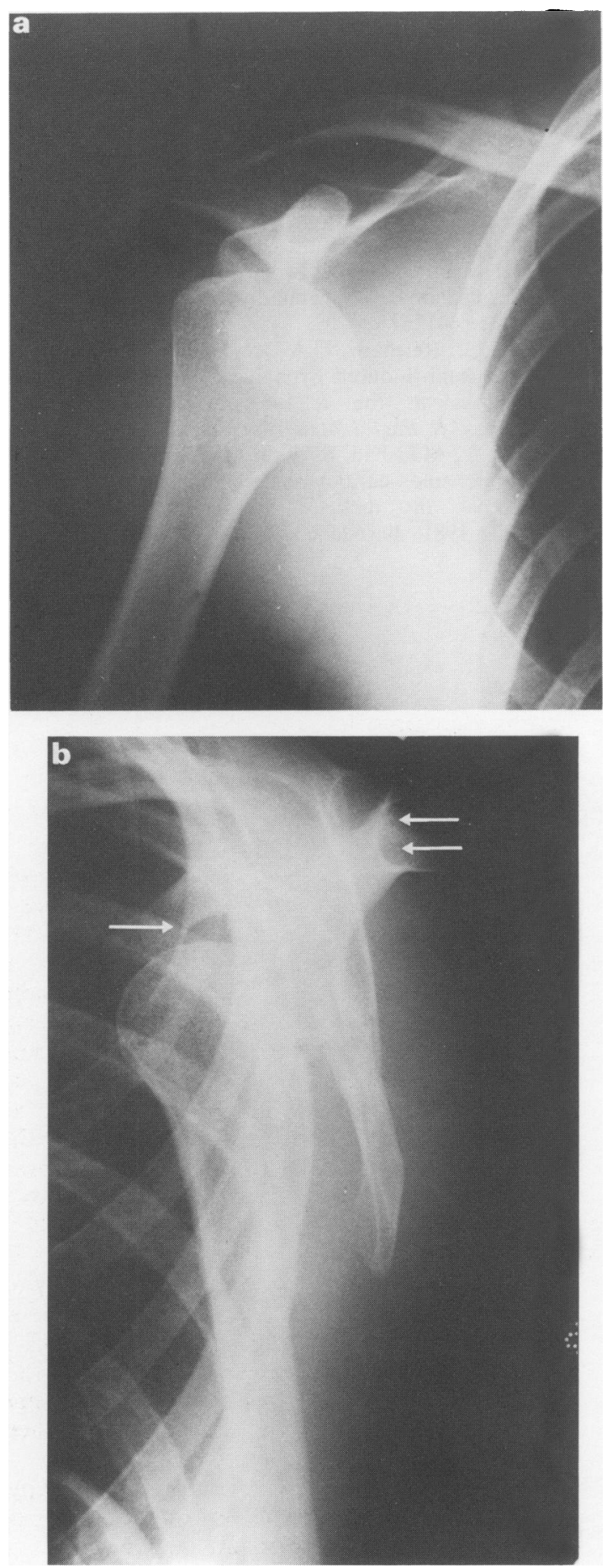

Figure 1 Pre-reduction radiographs: (a) anteroposterior view; (b) lateral scapular view. The humeral head normally lies centrally between the coracoid process $(\rightarrow)$ anteriorly, and the acromion/spine of the scapula $(\leftarrow)$ posteriorly. no further episodes and because there was no evidence to implicate other common causes of seizure, it is most likely that this was an isolated convulsion related to hypoglycaemia.

Nocturnal hypoglycaemia is a recognized problem in insulin-dependent diabetics. It is said to be more prevalent if the bedtime blood glucose concentration is below $7 \mathrm{mmol} / 1$ in children ${ }^{2}$ and $6 \mathrm{mmol} / 1$ in adults. ${ }^{3}$ Our patient's blood glucose was below this level, although his glycosylated haemoglobin concentration is not suggestive of chronic hypoglycaemia. The classical modes of presentation of nocturnal hypoglycaemia are morning headache or nightmares or sweats which may wake the victim. Our patient frequently woke at night feeling 'weak and hungry', particularly if he had not eaten before retiring, and on the morning of admission, he woke feeling 'groggy' and was aware that he had had a restless night.

Alcohol potentiates the hypoglycaemic action of insulin ${ }^{4}$ by inhibiting hepatic gluconeogenesis, ${ }^{5}$ and it is significant that he drank three glasses of wine during the evening.

Some insulin-dependent diabetics not only have an impaired ability to prevent hypoglycaemia, ${ }^{6}$ but may also develop neuroglycopenia at higher plasma glucose levels than would normally be expected. ${ }^{7}$ Convulsions may, therefore, follow a modest fall in blood glucose.

If the diabetes is of more than two years duration (7 years in this case), the glucagon response to insulin-induced hypoglycaemia is generally reduced, ${ }^{8}$ but a normal catecholamine response provides adequate protection. This is mediated via the sympathetic nervous system which acts directly on the adrenal medulla. It wanes after approximately 15 years, ${ }^{9}$ probably as a feature of autonomic neuropathy. ${ }^{10}$ If spontaneous glucose recovery is postulated, adequate counter-regulatory mechanisms must have existed, otherwise recovery could not have occurred. Excessive insulin action must therefore have initially overcome the protective mechanisms.

Because of the regularity of his nocturnal symptoms, this patient's insulin regime was clearly unsuitable. Monotard insulin has a peak of activity between 6 and 14 hours and a duration of 12 to 24 hours.

The delay in recognition of bilateral dislocation of the shoulders was due to a low index of suspicion. Many of the published cases have not been diagnosed until much later (as long as 6 weeks in one instance), thereby necessitating operative reduction.

\section{Acknowledgements}

With thanks to Dr K.G. Taylor for his advice, and Mrs Dilys Thomas for her secretarial skills. 


\section{References}

1. Brown, R.J. Bilateral dislocation of the shoulders. Injury 1976, 15: 267-273.

2. Whincup, G. \& Milner, R.D.G. Prediction and management of nocturnal hypoglycaemia in diabetes. Arch Dis Child 1987, 62: 333-337.

3. Pramming, S., Thorsteinsson, B., Bendtson, I., Ron, B. \& Binder, C. Nocturnal hypoglycaemia in patients receiving conventional treatment with insulin. $\mathrm{Br}$ Med $J$ 1985, 291: 376-379.

4. Arky, R.A., Feverbrants, E. \& Abramson, E.A. Irreversible hypoglycaemia. A complication of alcohol and insulin. JAMA 1968, 206: 575-578.

5. Marks, V. Alcohol and carbohydrate metabolism. Clin Endocrinol Metab 1978, 7: 333-349.

6. Bolli, G., De Feo, P., Compagnucii, P. et al. Abnormal glucose counter-regulation in insulin dependent diabetes mellitus. Interaction of anti-insulin antibodies and impaired glucagon and epinephrine secretion. Diabetes 1983, 32: 134-141.
7. Santiago, J.V., White, N.H., Skor, D.A. et al. Defective glucose counter-regulation due to glucagon and epinephrine secretory responses limits the intensive therapy of insulin dependent diabetes mellitus. Am J Physiol 1984, 247: 215-220.

8. Bolli, G., De Feo, P., Compagnucii, P. et al. Important role of adrenergic mechanisms in acute glucose counter-regulation following insulin induced hypoglycaemia in type I diabetes. Evidence for an effect mediated by beta-adrenoreceptors. Diabetes 1982, 31: 641-647.

9. Boden, G., Reichard, G.A. Jr., Hoeldtke, R.D. et al. Severe insulin induced hypoglycaemia associated with deficiencies in the release of counter-regulatory hormones. $N$ Engl J Med 1981, 305: 1200-1205.

10. Hilsted, J., Madsbad, S., Krarup, T. et al. Hormonal, metabolic and cardiovascular responses to hypoglycaemia in diabetic autonomic neuropathy. Diabetes 1981, 30: 626-633. 